\title{
Erratum to: Parentage analysis in a managed free ranging population of southern white rhinoceros: genetic diversity, pedigrees and management
}

\author{
Abigail S. Guerier · Jacqueline M. Bishop • \\ Stuart J. Crawford · Anne Schmidt-Küntzel • \\ Ken J. Stratford
}

Published online: 24 August 2012

(C) Springer Science+Business Media B.V. 2012

\section{Erratum to: Conserv Genet (2012) 13:811-822 \\ DOI 10.1007/s10592-012-0331-4}

In our paper we state that the two introduced rhinoceros bulls were 'successfully breeding with resident females within 6 months, well before establishing their own home territories.' However, the first calves sired by introduced bulls Tony and Jeff were born in 2006, and hence the first successful conceptions were within 26 months of the bulls' arrival in 2002, not 6 months as we stated.

The online version of the original article can be found under doi:10.1007/s10592-012-0331-4.

A. S. Guerier · K. J. Stratford ( $\square)$

Ongava Research Centre, PO Box 58, Okaukeujo, Namibia

e-mail: kenjstratford@gmail.com

\section{A. S. Guerier}

Mammal Research Institute, Department of Zoology and

Entomology, University of Pretoria, Pretoria 0002, South Africa

J. M. Bishop

Department of Zoology, University of Cape Town, Private Bag

X3, Rondebosch, Cape Town 7700, South Africa

\section{S. J. Crawford}

Ongava Game Reserve, PO Box 640, Outjo, Namibia

A. Schmidt-Küntzel

Life Technologies Conservation Genetics Laboratory, Cheetah

Conservation Fund, PO Box 1755, Otjiwarongo, Namibia
Importantly, by 2004 these new bulls still had not established independent home ranges. Indeed, in 2004 Tony's home range overlapped completely with that for the remaining founder bull Derek. It was not until 2006 that the introduced bull Tony first patrolled his own home range outside that of the founder bull, with the other introduced bull Jeff taking a further year to establish his own home range. Thus our point remains-introduced bulls were successfully breeding with resident females well before establishing their own home territories. 